\title{
Congenital Malalignment of the Nails
}

\author{
Anca Chiriac ${ }^{1,2,3}$, Adrian Năznean ${ }^{4}$, Cristian Podoleanu5, Claudiu Molnar6, Simona Stolnicu7,8 \\ 1 Department of Dermatology, Nicolina Medical Center, Iași, Romania \\ 2 Apollonia University, lași, Romania \\ 3 “P. Poni” Research Institute, Romanian Academy, Iași, Romania \\ 4 Department of Foreign Languages, University of Medicine, Pharmacy, Sciences and Technology, Târgu Mureș, Romania \\ 5 Department of Internal Medicine, University of Medicine, Pharmacy, Sciences and Technology, Târgu Mureș, Romania \\ 6 Department of Gynecology, University of Medicine, Pharmacy, Sciences and Technology, Târgu Mureș, Romania \\ 7 Department of Pathology, University of Medicine, Pharmacy, Sciences and Technology, Târgu Mureș, Romania \\ 8 Histopat Invest Laboratory, Târgu Mureș, Romania
}

\section{CORRESPONDENCE}

\section{Cristian Podoleanu}

Str. Gheorghe Marinescu nr. 38

540139 Târgu Mureș, Romania

Tel: +40 265215551

E-mail: podoleanu@me.com

\section{ARTICLE HISTORY}

Received: September 2, 2018

Accepted: December 11, 2018
Anca Chiriac • Str. Hatman Șendrea nr. 2, 700613 lași, Romania. Tel: +40332808703

Adrian Năznean - Str. Gheorghe Marinescu nr. 38 , 540139 Târgu Mureș, Romania. Tel: +40 0265215551 Claudiu Molnar • Str. Gheorghe Marinescu nr. 38 540139 Târgu Mureș, Romania. Tel: +40 0265215551 Simona Stolnicu • Str. Gheorghe Marinescu nr. 38 540139 Târgu Mureș, Romania. Tel: +40 0265215551

\section{ABSTRACT}

Congenital malalignment of the toenail is characterized by the lateral (rarely medial) deviation of nail plates that affects mostly the great toes from one foot or both, but has also been described on other toes, even on the hands. This nail disease is still considered a rare entity, although it is not a rare clinical observation in daily practice. We present a few cases in children and adults, highlighting the diagnosis made by clinical observation, regardless of the different grades of severity of the nail disease. Conclusion: It is of great importance to clinically recognize this entity in young children and to make the correct recommendations.

Keywords: nail, disorders, development, defects

\section{INTRODUCTION}

The first description of the nail disorder was done in 1978 by Samman, who named it "great toenail dystrophy". ${ }^{1}$ In 1979, Baran gave the disorder its actual name: "congenital malalignment of the big toenail".2

Although initially considered a rare congenital disease, affecting only the great toenails of both genders, during the last decades, more and more reports have been published, describing cases affecting other nails of the feet or hands, and not only congenital but also acquired forms. ${ }^{3}$

Diagnosis is made by clinical observation, regardless of the different grades of severity of the nail disease. The mild form cannot be observed until puberty or adulthood, although the nail changes are present at birth. This form is characterized by minor displacement of the nail, without characteristic changes in the nail plate, and remains undiagnosed during childhood; it is more common in both great toenails as external deviation of the nail plate with hyperkeratosis and shorter aspect; medial deviation is extremely rare. Unilateral cases can occur, more often affecting the right great toenail (Figure 1A, 1B, 1C). ${ }^{4,5}$ Esthetic 


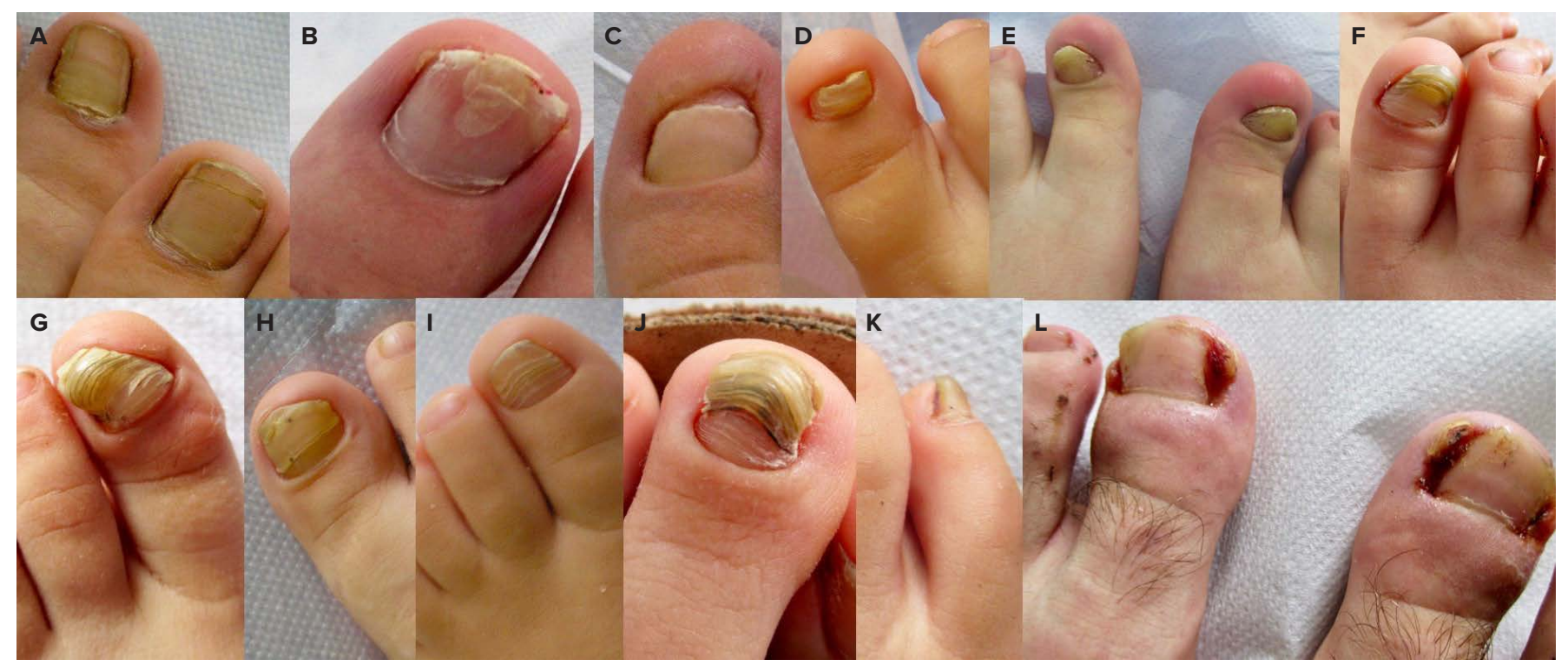

FIGURE 1. Congenital malalignment of the great toenail at puberty. A - Bilateral congenital malalignment of the great toenail with hyperkeratosis and nail discoloration; B - Unilateral congenital malalignment of the great toenail; $\mathbf{C}$ - Short and hyperkeratotic deviated nail; D - Malalignment of the great toenail in early infancy; E - Bilateral congenital malalignment of the great toenail in a 2-year-old boy; $\mathbf{F}$ - Triangular or trapezoid shape of the nail plate and deviated nail plate in a child; $\mathbf{G}$ - "Oyster shell-like appearance" in a child; $\mathbf{H}$ - Onychomadesis associated with congenital malalignment of the great toenail in a child; I - Transversal grooves or ridges on the nail plate in a child; $\mathbf{J}$ - Congenital malalignment of the second toenail in a child; $\mathbf{K}$ - Congenital malalignment of the fifth toenail in a child; $\mathbf{L}-$ Acute bilateral paronychia in a teenager (17-year-old male) diagnosed since birth with congenital malalignment of the great toenail

concerns and/or previous extended antifungal treatments with no efficacy represent the main causes of seeking medical advice.

The classic form of malalignment of the great toenail is diagnosed based on the following criteria: ${ }^{2-5}$

- it is noticed at birth or in early infancy (Figure 1D);

- it is bilateral in the majority of cases (Figure 1E);

- the nail plate has a triangular or trapezoid shape and is shorter than normal or than the other nails (Figure $1 \mathrm{~F})$;

- nail plate hyperkeratosis aggravates with age and chronic trauma, and it can have an "oyster shell-like appearance” (Figure 1G); onychogryphosis can be a severe complication;

- onycholysis and onychomadesis can be associated in complicated cases (Figure 1H);

- nail discoloration is a distinctive feature, varying from brown, gray, green due to thickened nail plate, and fungal or Pseudomonas infection;

- transversal grooves or ridges can cross the nail plate (Figure 1I).

Apart from the congenital malalignment of the great toenail, the condition can be extremely rarely diagnosed on other toenails, uni- or bilateral (Figure 1J, 1K).
The etiology and pathogenesis of the disorder are still unknown; clinical appearance is explained by deviation of the growth axis of the nail plate related to the longitudinal axis of the distal phalanx. ${ }^{3}$

An autosomal dominant inheritance with variable penetrance has been postulated in some cases, ${ }^{6}$ and further genetic clinical examination is recommended.

Therapeutic approach, especially in small children, should be done carefully in order to avoid unnecessary diagnostic tests (mycological examination, nail biopsy) and aggressive curative methods. In cases with minimal deviation, in the absence of any sign of complication and bearing in mind that spontaneous improvement is reported in many cases before puberty, surveillance is recommended.7 Surgical correction is the mainstay of therapy in severe cases, preventing complications such as acute paronychia (Figure 1L).

\section{CONCLUSION}

It is of great importance to clinically recognize this entity in young children and to make the correct recommendations.

\section{CONSENT TO PARTICIPATE}

Informed consent to publish the case was obtained from the parents. 


\section{CONFLICT OF INTEREST}

None for all authors.

\section{REFERENCES}

1. Samman PD. Great toe nail dystrophy. Clinical and Experimental Dermatology. 1978;3:81-82.

2. Baran R, Bureau H, Sayag J. Congenital malalignment of the big toe nail. Clinical and Experimental Dermatology. 1979;4:359-360.

3. Chieco P. Congenital malalignment of the great toenail. Eur J Pediat Dermatol. 2013;23:5-8.

4. Wagner $G$, Sachse MM. Congenital malalignment of the big toe nail. $J$ Dtsch Dermato/ Ges. 2012;10:326-30

5. Batalla A, Curto JR. Congenital malalignment of the great toenail. Report of two cases. Dermatol Online J. 2014;20:21251.

6. Kus S, Tahmaz E, Gurunluoglu R, Candan I, Uygur T. Congenital Malalignment of the Great Toenails in Dizygotic Twins. Pediatric Dermatology. 2005;22:434-435.

7. Senayli A, Sezer E, Sezer T, Senayli Y, Yuksek J. Coexistence of congenital malalignment of the great toenails with ocular melanocytosis. Eur $J$ Dermatol. 2008;18:208-209. 